\title{
Design of a new fast tool positioning system and systematic study on its positioning stability
}

\begin{abstract}
The challenge of maintaining good surface quality under high operational frequencies in freeform machining invokes the need for a deterministic error analysis approach and a quantitative understanding on how structural design affects the positioning errors. This paper proposes a novel stiff-support positioning system with a systematic error analysis approach which reveals the contributions of disturbances on the tool positioning errors. The new design reduces the structural complexity and enabled the detailed modelling of the closed loop system. Stochastic disturbances are analysed in the frequency domain while the non-stochastic disturbances are simulated in the time domain. The predicted following error spectrum agrees with the measured spectrum across the frequency range and this approach is justified. The real tool positioning error, which is free from sensor noise, is revealed for the first time. The influences of moving mass under various bandwidth settings have been studied both theoretically and experimentally. It is found that a larger moving mass helps combating disturbances except the sensor noises. The influences of cutting force are modelled and experimentally verified in the micro lens array cutting experiments. The origins of the form errors of the lenslet are discussed based on the error analysis model.
\end{abstract}

Keywords: freeform machining, positioning stability, following error, error analysis, fast tool servo

\section{Introduction}

Driven by the ever increasing demands for multi-functional and light-weight products, more and more next generation optical products are designed to possess complex freeform shapes [1-3]. Freeform optics are critical elements to the development of emerging holographic displays, head-up displays and intra-ocular-lens as they offer more freedoms for light control and allow lower wave front distortions than conventional spherical and aspherical optics [4]. However, the complexity of the freeform optics design poses significant manufacturing challenges to current freeform diamond turning [5,6], grinding [7] and micro structuring techniques $[8,9]$. Tool tip vibration is directly related to the closed loop stability of the positioning system and it greatly affects the surface finish of the machined parts [10]. Current ultra-precision machine tools tend to adopt large slides to make the most of the averaging effect [11] and to achieve high positioning stability. When the machine slides are minimised in fast servo applications for high dynamic machining, the environmental disturbances start to affect the positioning accuracy. Special isolation measures can be taken but it will introduce extra costs [12]. 
The challenge in maintaining good surface quality under high operational frequency invokes the need of a systematic error control approach to predict and reduce the dynamic error for freeform machining.

Currently, Slow Tool Servo (STS) and Fast Tool Servo (FTS) are two major freeform diamond turning techniques. In STS, the diamond tool is moved by the machine slide in synchronise with the rotation of the spindle. The STS method can machine parts with large deviations in the scale of millimetres. However, it has low machining efficiency with a long cycle time, as the machine can only be operated at a motional frequency lower than $5 \mathrm{~Hz}$ [13]. FTS uses piezo or voice coil motors to actuate the diamond tool with high control bandwidth. Nowadays, very high frequency motion, up to $20 \mathrm{kHz}$, has been achieved by FTS technique [14-16]. However, the current design focus for FTS system is on achieving high acceleration with minimal moving mass. The side effects of low moving mass haven't been discussed. Understanding of the dynamic interactions between the mechanical and control systems and how the mechanical structural design affects positioning accuracy is also a knowledge gap.

This paper presents a new stiff-support structure for freeform diamond turning and a systematic error analysis approach to predict positioning errors. Mathematical model is compared against the measured response data of the prototype to ensure accurate modelling. The differences between closed loop following error and real tool positioning error are clarified and the frequency domain synthesis approach is proposed for both errors. In order to reduce the errors from the design point of view, the influences of moving mass are quantitatively analysed. Then a series of closed loop positioning tests are designed to verify this approach. The influences of cutting force are also taken into account in the model. Lastly, micro lens array structures are fabricated and the form errors are evaluated against the analysed results.

\section{Stiff-support structural design and prototyping}

\subsection{Stiff-support structural design}

Traditionally, FTS device is designed as an additional module and mounted on the carriage of an ultraprecision machine tool. This module is responsible for generating high frequency and small range motions, while large range motion is provided by the machine tool slides. For conventional FTS design as shown in Fig. 1 a), the feedback sensor measures the displacement of the tool reference to the FTS base. The FTS is usually installed with a certain elevated height above the slide. Therefore there exist at least one angular and one translational degree of freedoms which are less stiff. Because of the finite stiffness of the underneath bearing or 
servo system, the base of the FTS module will vibrate during high frequency cutting. Counter balancing measures can be taken [17] but with either reduced motion bandwidth or doubled system cost. Nevertheless, the disturbances from cutting force still pose a problem.

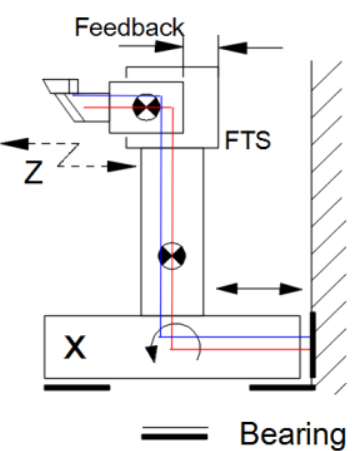

a) Conventional FTS
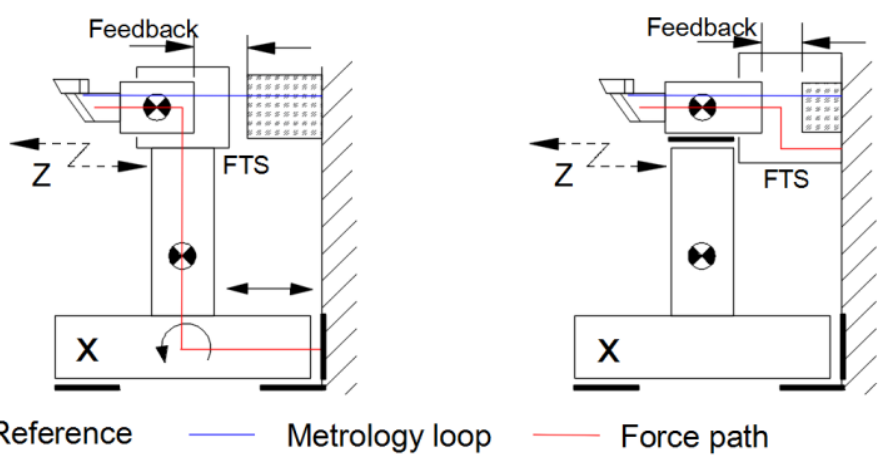

Force path

b) FTS with metrology frame $\quad$ c) Proposed stiff support design

Fig. 1. Structural loop comparison of different FTS configurations

With the addition of the metrology frame close to the cutting tool, as shown in Fig. $1 \mathrm{~b}$ ), this movement can be detected because it will cause linear motion error at the measuring point. However, the cutting force will travel through all the bearing interfaces to the machine base and cause vibrations. The exited vibrations will behave as disturbances to the control system and lead to positioning errors.

In this paper, a new configuration is proposed, as shown in Fig. $1 \mathrm{c}$ ), the inertial force and cutting force are directly guided to the fixed frame. With no flexible mode prone to be excited by the forces, the requirement on counter balancing is thus greatly reduced. The dynamic characteristics are therefore expected to be simpler together with reduced modelling difficulties.

This configuration is made feasible by the design of a flat Lorentz actuator, as shown in Fig. 2 a). Single phase flat voice coil motor is extended along the $\mathrm{X}$ direction to release the motion degree of freedom which is usually constrained in traditional design. Short stroke high frequency motion is achieved in the $\mathrm{Z}$ direction with flexure guidance. The flexure guidance is fixed on the carriage of the $\mathrm{X}$ guide slide as shown in Fig. $2 \mathrm{~b}$ ). The motion along the $\mathrm{X}$ direction is driven by a linear motor and guided by mechanical linear slide. 


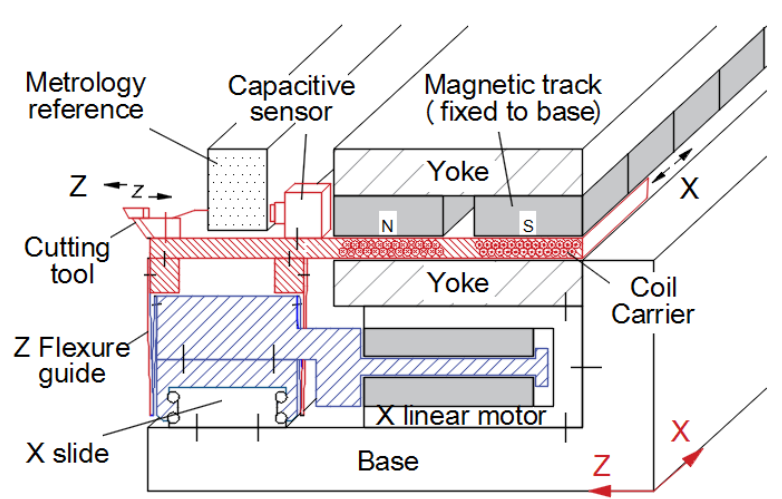

a) Cross section of the proposed stiff-support structure

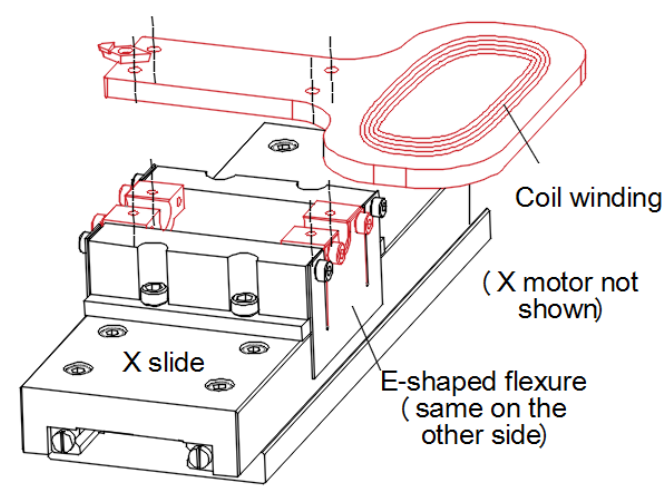

b) Detailed design of the flexures

Fig. 2. Stiff-support structural design (Parts in red move in the $\mathrm{Z}$ direction and parts in blue move in the $\mathrm{X}$ direction together with the red parts.)

One of the advantages for this design is that the straightness and stiffness of the $\mathrm{X}$ linear slide become less important than those in a conventional ultra-precision diamond machine. This makes it possible to use low cost ball bearing slides as the $\mathrm{X}$ axis guidance and easy to achieve compact size. Also, the stiff support design reduces the need for counter balancing the inertia forces. The proposed machine setup is shown in Fig. 3. The designed module is fixed to the machine bed directly. A separate metrology frame forms the shortest metrology loop to the spindle. The large range slow motion is provided by the spindle support while the small fast $\mathrm{Z} 2$ motion can be used to correct the other errors. Abbe principle is obeyed in this design along the $\mathrm{Z}$ direction which is very important in reducing machine tool errors $[18,19]$.

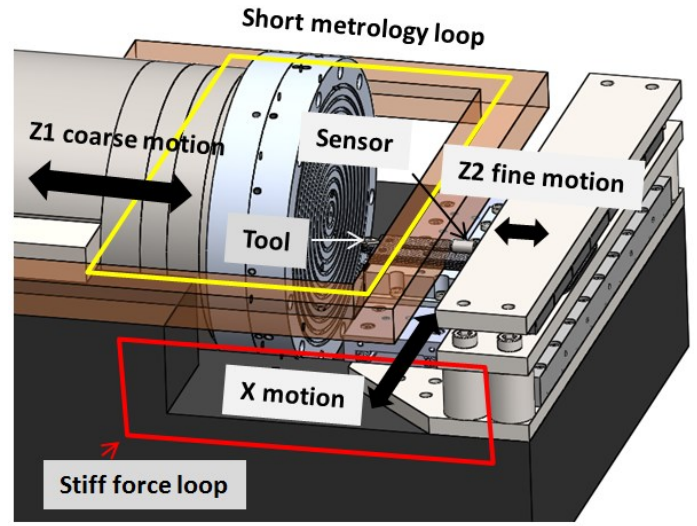

Fig. 3. A diamond turning machine setup with metrology reference and stiff force loop

\subsection{Development of positioning system prototype}

A motion system prototype is developed according to the stiff-support structural design, shown in Fig. 4. A total of fourteen N52 grade NeFeB magnetics are bonded onto two steel bars to form the magnetic track. The motor coil support is made of four layers of carbon fibre sheets to minimise the mass of the non-force- 
generating parts. Each layer is bonded with resin epoxy. The bonding layer is intended to increase the damping of the support structure. A capacitive sensor with a noise floor of $1 \mathrm{~nm}$ at $15 \mathrm{kHz}$ bandwidth (Lion Precision CPL190) is fixed to the moving coil carrier and targeting a ground flat surface. The ground and lapped surface is used as the position reference and the averaging effects of the capacitive sensing area helps reducing the influences of lapping marks. A linear cross roller bearing from THK is used as the X guide. A pair of E-shaped flexure hinge is cut from beryllium copper and used to support the coil assembly. The $\mathrm{Z}$ motion range is $50 \mu \mathrm{m}$ limited by the measurement range of the capacitive sensor.

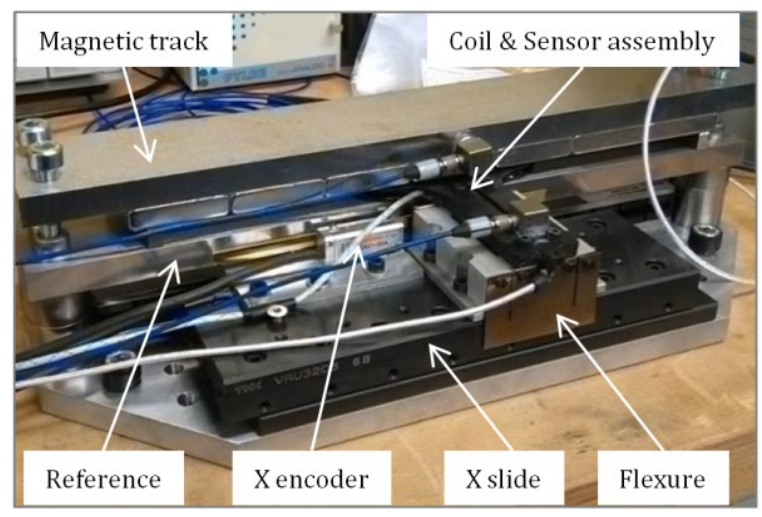

Fig. 4. Photo of the motion system prototype

A customised digital controller board is built using a dual core $1 \mathrm{GHz}$ digital signal processor (DSP) from Taxes Instruments (TMS320C6657). A closed loop current control board is built using analogue components. The current loop bandwidth is measured to be $400 \mathrm{kHz}(-3 \mathrm{~dB})$.

\section{Positioning error analysis and study on influencing factors}

\subsection{Modelling of the mechatronic system with error sources}

The dynamic model of the mechatronic system is established in this section. This model is used for two purposes, one of which is to compare it with the real device response and get more accurate parameter estimation. The second purpose is to use this model as the basis for error analysis. Fig. 5 shows the closed loop diagram of this tool positioning system. It mainly consists of a digital controller with $\mathrm{A} / \mathrm{D}$ and $\mathrm{D} / \mathrm{A}$ convertors, a power amplifier stage, the mechanical device with a motor and a displacement sensor. 


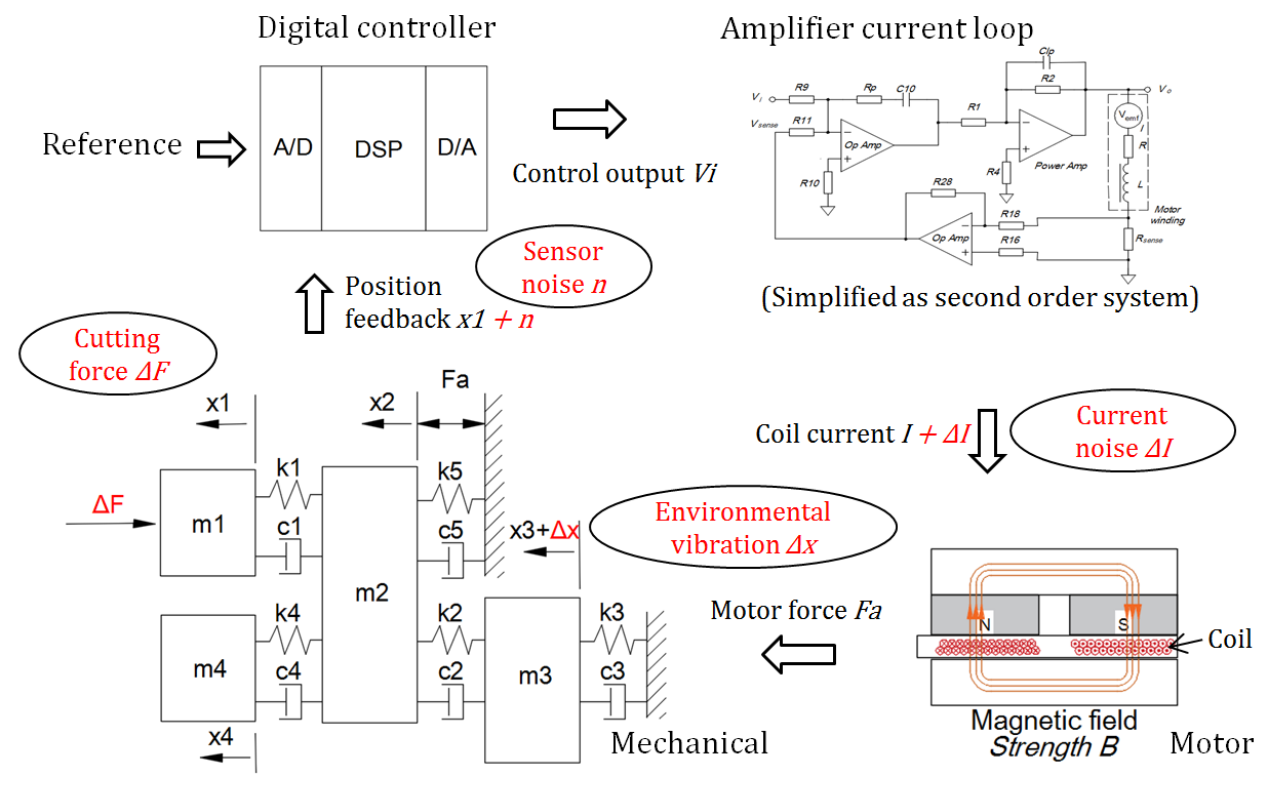

Fig. 5. Closed loop diagram of the developed tool positioning system

The mechanical device is represented as a general lumped parameter model in Fig. 5. The $m 1$ block represents the tool and $m 2$ is the mass of the movable body including coil assembly and sensor. $k 2$ and $c 2$ are the stiffness and damping coefficients of the flexure bearing. $m 3$ represents the mass of the $\mathrm{X}$ carriage. $m 4$ represents any flexible parts that will disconnect from $m 2$ at high frequencies. It is possible that there are multiple $m 3$ and $m 4$ in practice but only the dominant one is modelled here. $k 5$ and $c 5$ are the stiffness and damping coefficients of the motor coil reference to the magnetics. The power amplifier stage is simplified as a controlled current source with second order low pass characteristics. The motor is shown as a flat voice coil motor with uniform magnetic fields across the coil winding.

The major disturbance sources are shown in Fig. 5 as well. The disturbance sources are identified as sensor noise $n$, cutting force $\Delta F$, current noise $\Delta I$ and environmental vibration $\Delta X$. The identified source might be the net effects from several origins and they are such selected for ease of measuring. The current noise $\Delta I$ includes all the noises from D/A convertor and other electronic transmissions. The transfer functions from disturbances to tool tip position $x 1$ are derived as below ( $s$ is the complex frequency in Laplace transform, $Z(s)$ is introduced to simplify the representation):

$$
\begin{gathered}
\frac{X_{1}(s)}{\Delta F(s)}=1 /\left[Z(s) \times\left(k_{1}+c_{1} s\right) /\left(Z(s)+k_{1}+c_{1} s\right)+m_{1} s^{2}\right] \\
\frac{X_{1}(s)}{\Delta F a(s)}=k_{1} /\left[Z(s)\left(k_{1}+c_{1} s+m_{1} s^{2}\right)+\left(k_{1}+c_{1} s\right) m_{1} s^{2}\right] \\
\frac{X_{1}(s)}{\Delta X(s)}=k_{1}\left(k_{2}+c_{2} s\right) /\left[Z(s)\left(k_{1}+c_{1} s+m_{1} s^{2}\right)+\left(k_{1}+c_{1} s\right) m_{1} s^{2}\right]
\end{gathered}
$$


Where $Z(s)$ is denoted as:

$$
Z(s)=\frac{\left(k_{4}+c_{4} s\right) m_{4} s^{2}}{k_{4}+c_{4} s+m_{4} s^{2}}+\frac{\left(k_{3}+c_{3} s+m_{3} s^{2}\right)\left(k_{2}+c_{2} s\right)}{k_{3}+c_{3} s+m_{3} s^{2}+k_{2}+c_{2} s}+k_{5}+c_{5} s+m_{2} s^{2}
$$

The transfer function from controller output voltage $V_{i}$ to motor current $I$ is modelled as

$$
\frac{I(s)}{V_{i}(s)}=\frac{G_{I} \times \omega_{I}^{2}}{\left(s+\omega_{I}\right)^{2}}
$$

Where $G_{I}$ is the DC gain of the current loop controller and $\omega_{I}$ is the bandwidth.

The average magnetic field strength between the magnetic tracks is $B$ Tesla. The effective length of the coil, which cuts the magnetic lines when the motor moves, is denoted as $l$. Then the motor force is

$$
F_{a}(s)=B \times l \times I(s)
$$

The capacitive sensor is modelled as a second order low pass filter. The sensor output voltage is

$$
\frac{V_{s}(s)}{X_{1}(s)}=\frac{\omega_{s}^{2} S}{\left(s+\omega_{s}\right)^{2}}
$$

Where $S$ is the sensitivity of the sensor and $\omega_{s}$ is the instrument bandwidth in $\mathrm{rad} / \mathrm{s}$.

The system mathematical model is used as a grey-box model for parameter identification purpose. System identification process is necessary because the built system may deviate from the designed parameters. Sweep sinusoidal commands are sent from the $\mathrm{D} / \mathrm{A}$ convertor and the response of the open loop system is measured by the capacitive displacement sensor. The model parameters are then estimated by fitting the grey box model and the experimental data in MATLAB. The estimated open loop transfer function is shown to be of $97.7 \%$ fit to the measured data in Fig. 6, which is evaluated by the normalized root mean square error between the model prediction and measured data.

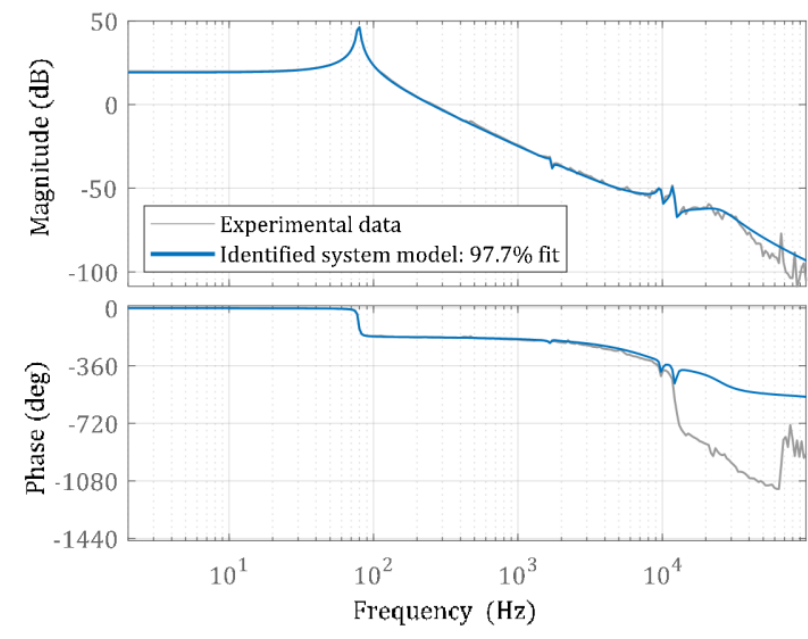

Fig. 6. Grey box model estimation result compared with experimental data 
The control action in the digital processor is one of the signal chains in the closed loop. Before the closed loop transfer functions can be derived, the controller structure and parameters have to be determined first. Here PID control algorithm is adopted. Although H2 optimal control algorithm can theoretically minimise the effects of all disturbances, it is not adopted in this work because of its occasional instability in practice. The details of this optimal control algorithm can be found in Zhou and Doyle's book[20]. The PID controller gains are calculated using the MATLAB patented algorithm based on the measured open loop transfer function [21].

\subsection{Error evaluation method}

The disturbances can be treated as stochastic noises superimposed on slow varying non-stochastic components. The stochastic components don't repeat themselves in each measurement but they pose stable statistics characteristic like Power Spectrum Density (PSD) functions. For example, the electrical noise from a sensor is random but its thermal drift is predictable and repeatable. The PSDs of the stochastic components of the disturbances from sensor, current noise and environmental vibration are denoted as $W s, W i$ and $W g$ respectively, which are all functions of frequencies. The cutting force disturbance is treated as non-stochastic of value $\Delta F$.

The stochastic components of cutting force is set to zero at this point because cutting force is primarily determined by the cutting area. Very precise prediction model of cutting force has been realised by Zhu et al [22] and thus it is not considered stochastic. Although in practice there may be some random factors, like material impurity or micro grain boundaries, they are not considered here due to the difficulty of modelling and measurement. The disturbance values are listed in Table 1.

Table 1 Disturbance sources

\begin{tabular}{lll}
\hline Disturbance source & $\begin{array}{l}\text { Stationary stochastic } \\
\text { components }\end{array}$ & Non-stochastic components \\
\hline Displacement sensor noise & $W s$ & Treated as position command \\
Motor current noise & $W i$ & 0 \\
Environmental base vibration & $W g$ & 0 \\
Cutting force & 0 & $\Delta F$ \\
\hline
\end{tabular}

Both kinds of components contribute to the positioning errors and machining errors of a machine tool. Due to the different natures of the components, they are treated separately. The stochastic components are manipulated in the frequency domain since they have stable PSDs. The non-stochastic components are analysed in the time domain. 


\subsubsection{Frequency domain synthesis of stochastic disturbances}

The modelling of the whole positioning system and the calculated control algorithm make it possible to analyse the noise propagation paths in the closed loop system. This is more comprehensive than considering the mechanical set-up or control algorithm alone. The disturbance propagation paths in the positioning system are shown in Fig. 7. The stochastic components of each disturbance source are measured beforehand under stationary conditions.

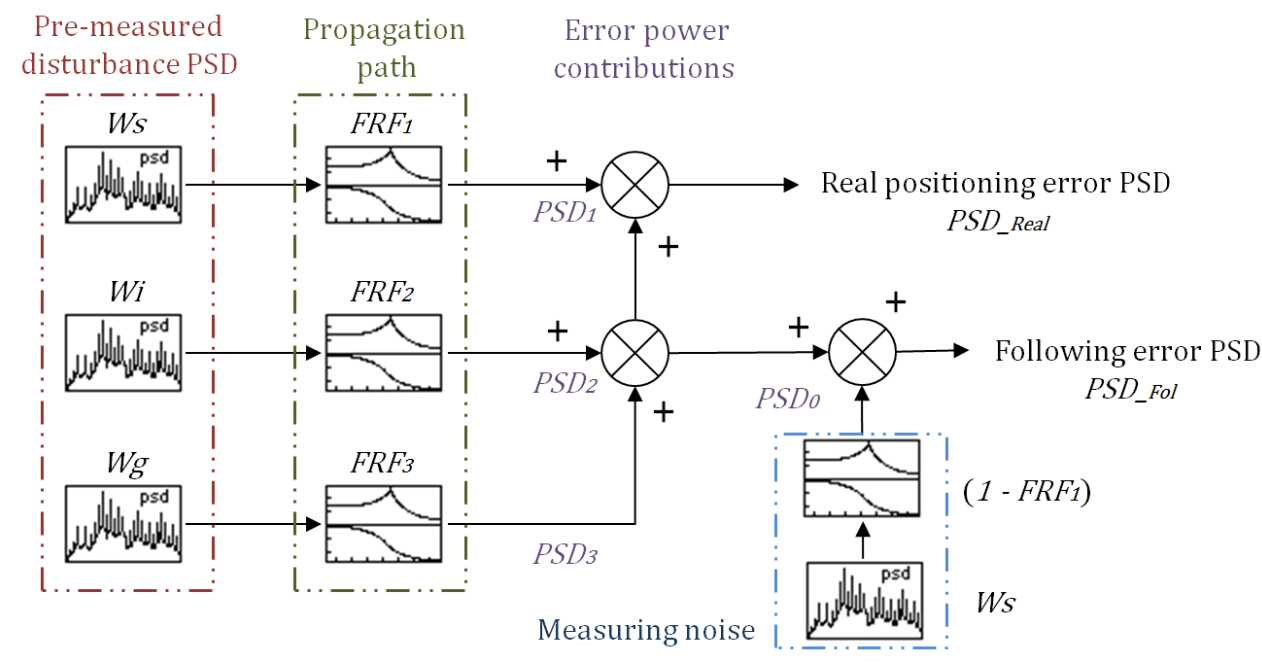

Fig. 7. Diagram of stochastic disturbance propagations and measuring noises

In this diagram, the $F R F_{i}$ represents the frequency response functions from each disturbance input to tool position, as modelled in section 3.1. In order to get better positioning stability, these transfer functions should be made as low as possible. The error power contribution $P S D_{i}$ from each disturbance to final position can be calculated according to [20] as:

$$
\operatorname{PSD}_{i}(v)=W_{i}(v) \times\left|F R F_{i}(v)\right|^{2}
$$

Where $i$ indicates the disturbance source number (from 1 to 3 with $W_{1}, W_{2}, W_{3}$ representing $W s, W i$ and $W g$, respectively) and $v$ is the frequencies. The $P S D_{i}$ represents the power spectrum density of the position errors caused by each disturbance source distributed across the frequency axis. Since these disturbances are assumed mutually uncorrelated, their powers can be added to reflect the total error power. The synthesised tool position PSD is

$$
P S D_{\text {Real }}(v)=P S D_{1}(v)+P S D_{2}(v)+P S D_{3}(v)
$$

The function $P S D_{\text {Real }}$ represents the true tool vibration spectrum. However, this value is not available in real applications. Most people use the position following error to indicate how accurate the tool is positioned. In a motion control system, following error is the instantaneous difference between the commanded position and 
the position as reported by the feedback sensor. It is commonly seen on the display screen of numerical control systems. Since every sensor has a certain level of noise floor, the reported position cannot represent the real tool position, especially in ultra-precision applications where the following errors is of the same level with sensor noises.

The following error can be estimated in a similar way as the real positioning error. The current noise and base vibration disturbance contribute the same amount of powers to the following error as to real positioning error. However, the sensor noise is treated differently. Since sensor noise is injected from the same location as the position reference in the loop, the sensor noise within the positioning bandwidth is tracked quite well and thus doesn't show up in the following error. Only the difference between the sensor noise and the tracked sensor noise contribute to the following error. Thus the following error PSD is calculated as

$$
\operatorname{PSD}_{F o l}(v)=W_{S}(v) \times\left|1-F R F_{1}(v)\right|^{2}+P S D_{2}(v)+P S D_{3}(v)
$$

In order to estimate the time domain error magnitude from the PSD values, the Cumulative Amplitude Spectrum (CAS) function is derived. $C A S_{i}(v)$ is the square root of the integrated $P S D_{i}(f)$ from $0 \mathrm{~Hz}$ to $v \mathrm{~Hz}$, shown in Eq.11.

$$
C A S_{i}(v)=\sqrt{\int_{0}^{v} P S D_{i}(f) d f}
$$

The squared CAS value at Nyquist frequency is equal to the total power. The square of the time domain Root Mean Square (RMS) value is also the signal power. According to Parseval's Theorem [23], the signal power remains the same in the frequency domain and time domain. Thus the error RMS value $E r r_{r m s}$ is expressed as

$$
E r r_{r m s}=C A S_{i}\left(v_{\text {Nyquist }}\right)
$$

Where $v_{\text {Nyquist }}$ is the Nyquist frequency. This relationship is used to link the estimated PSD function to time domain RMS error. The performance of the positioning system is evaluated by the RMS value of the real positioning error while the RMS following error is used to compare it with experimental results.

\subsubsection{Time domain analysis of non-stochastic components}

The non-stochastic component of the cutting force is predictable and repeatable. The time domain disturbance signal is directly used as an input to the disturbance transfer function. The outputs are the displacement deviations caused by the disturbance. The time domain simulation is run on MATLAB. 


\subsection{Analysis on influences of moving mass on positioning errors}

The positioning errors with different moving masses are analysed in this section using the established model. A pre-requisition for analysing positioning errors is the knowledge of disturbance strengths. Thus the disturbances are measured separately at each error source using data acquisition board and capacitive sensor as shown in Fig. 8. Thirty-two samples of each signal are measured under stationary conditions. The calculated power spectrum density functions are averaged to reduce measurement variance.

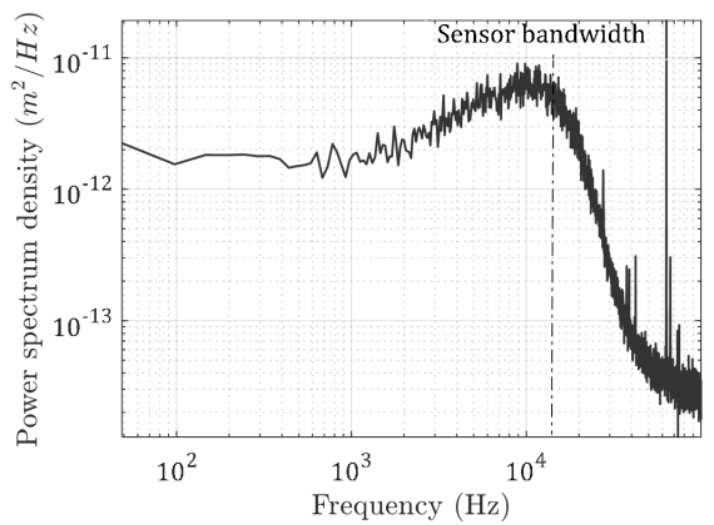

a) Displacement sensor noise $W s$

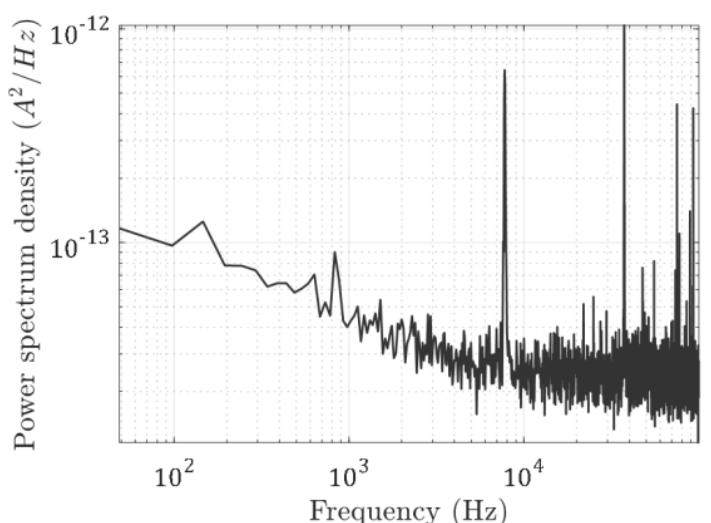

b) Motor current noise $W i$

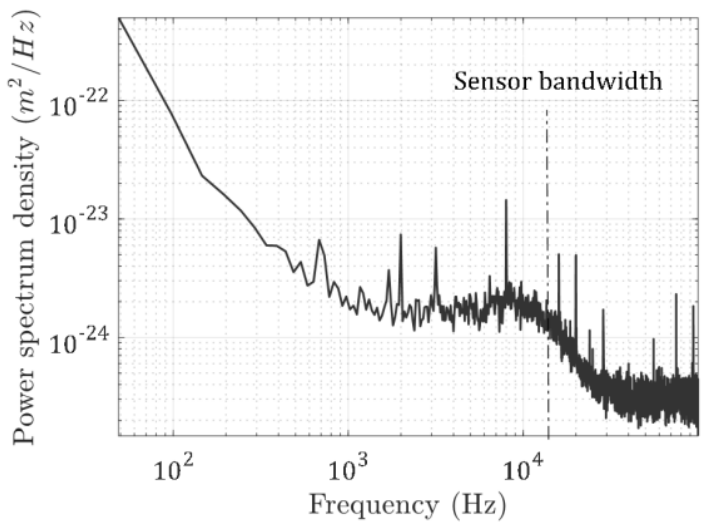

c) Environmental disturbance vibrations $\mathrm{Wg}$

Fig. 8. Disturbances measurement

The closed loop frequency response functions from each disturbance source to sensor voltage with two different moving mass are shown in Fig. 9 a). The closed loop bandwidth (-3dB) is kept the same at $468 \mathrm{~Hz}$ by changing the PID gains. It can be seen that when the total moving mass $m 1+m 2$ is increased, both the current noise and environmental vibration frequency response is lower than before. This means that the increased mass will help rejecting disturbances. The error power from sensor noise is the same because the closed loop bandwidth is unchanged. 
The CAS plot in Fig. 9 b) shows the error source contribution at each frequency calculated from the measured disturbances. It clearly shows that errors caused by both current noise and base vibration will be reduced. The expected RMS real positioning error will be reduced from $0.182 \mathrm{~nm}$ to $0.155 \mathrm{~nm}$.

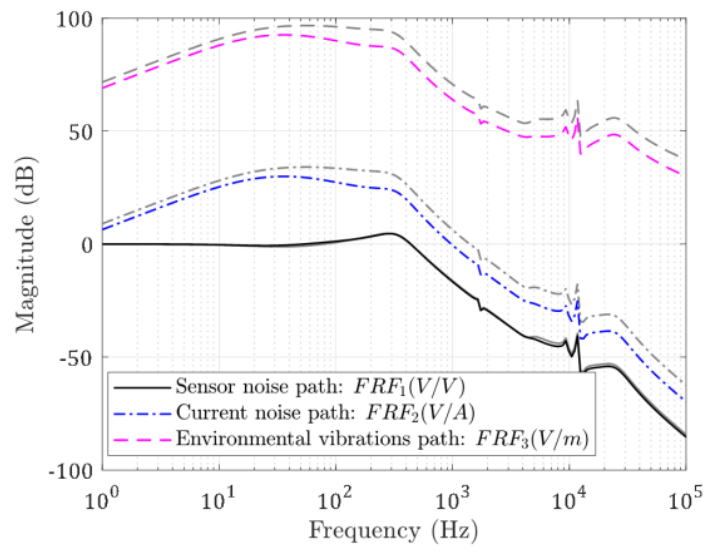

a) Frequency responses from disturbances to sensor voltage

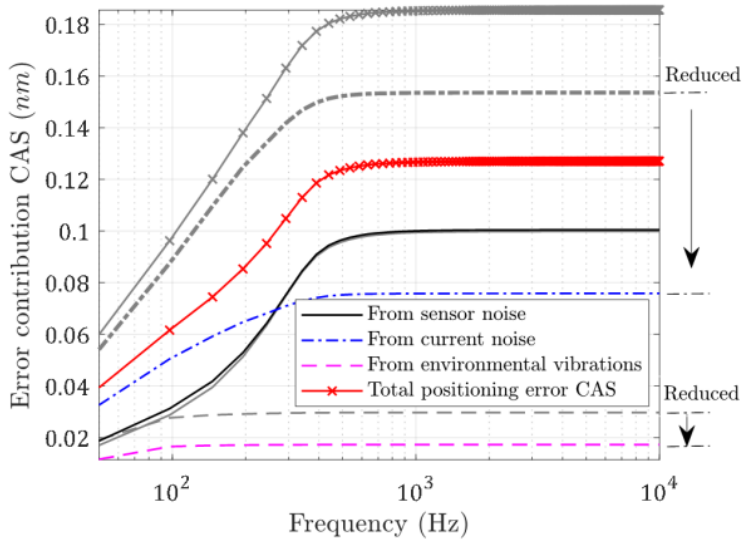

b) CAS of error source contributions

Fig. 9. Calculated frequency response and real positioning error CAS with increased moving mass (Grey: $0.075 \mathrm{~kg}$ moving mass; Coloured: $0.175 \mathrm{~kg}$ moving mass)

In Fig. 10 a), the estimated RMS values of the real positioning errors are plotted against the increasing closed loop bandwidths under different moving mass conditions. For each mass condition, the positioning error reaches a minimum value at some point. This is the optimal bandwidth for this mass condition. This optimal bandwidth becomes lower when the moving mass is larger. It is also seen that if the system is run at a bandwidth higher than $900 \mathrm{~Hz}$, increasing moving mass has very little effect. This is because in this region the major error source is the sensor noise whose contribution is dependent on bandwidth only. The estimated following error is also shown in Fig. 10 b). It shows the same trends as the real positioning error except the larger values and smaller variations.

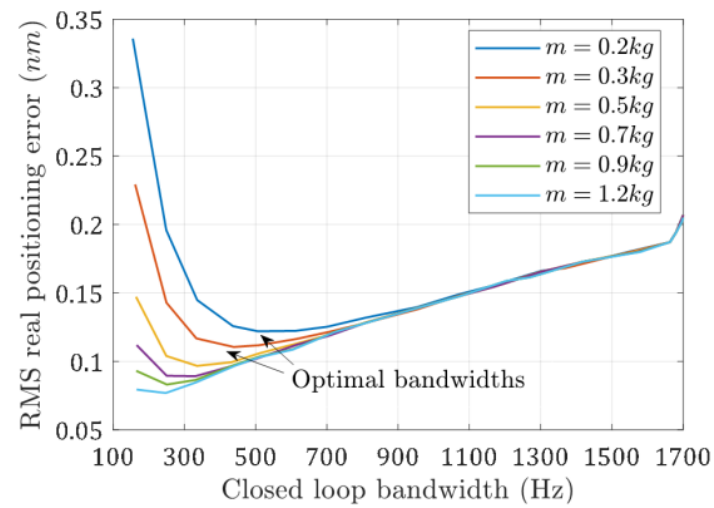

a) Estimated real positioning error

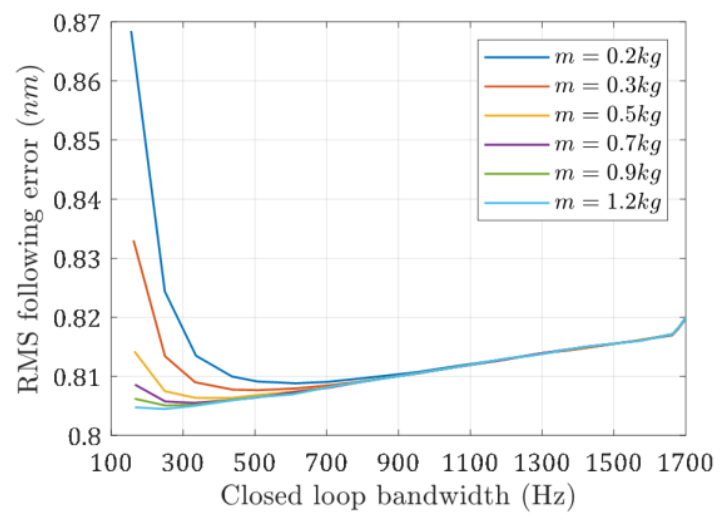

b) Estimated following error

Fig. 10. Comparison of errors with increased bandwidth under different moving masses 


\section{Experiments}

Two groups of experiments were undertaken to validate the error analysis approach. Firstly the stationary following errors under different moving masses were measured. Then the motion system was used to cut freeform micro lens array structures and the surface profile is measured to reflect the errors during dynamic machining.

\subsection{Closed loop positioning tests}

The calculated controller action was transformed into C language codes and deployed in the developed controller board. The closed loop update rate was set to $199.6 \mathrm{kHz}$ and the following error was acquired at the same rate. Each acquisition includes 4096 samples. The moving mass was changed by gluing additional steel blocks onto the tool holder symmetrically, minimising the change of the centre of gravity. Two different moving masses, namely $0.075 \mathrm{~kg}$ and $0.175 \mathrm{~kg}$, were achieved in this way. For each mass condition, the controller gains were adjusted from low to high, resulting in various cross over frequencies (or positioning bandwidths). Each following error measurement was repeated 32 times to reduce the influences of random factors.

\subsection{Micro lens array turning experiments}

The developed positioning device was installed on a diamond turning machine with its original slides disabled as shown in Fig. 11 b). Only the precision air bearing spindle was used in this experiment. The base of the device was fixed to the spindle housing through two enhancing bars to increase the structural rigidity. A dynamometer (Kistler 9129AA) was also mounted under the device. The cutting force profile of predefined shape was measured beforehand without the enhancing bars.

Micro lens array structure was machined onto the face of the workpiece. Firstly a round diamond tool was used to cut a flat surface with slow feed rate. Then the same tool was commanded to move in a sinusoidal way and the material was cut at the far end of the trajectory as shown in Fig 11 a). The cut is done at a relatively large radius. The depth of cut was selected as half of the sinusoidal amplitude and the cutting length was controlled to be the same with cutting width by adjusting the spindle speed. Therefore each lenslet resembles a micro spherical shape and was formed in a single tool path. The machining efficiency for this method is higher than multi-pass contouring method and it can be found in large area Roll-to-Roll mould producing processes [24]. 


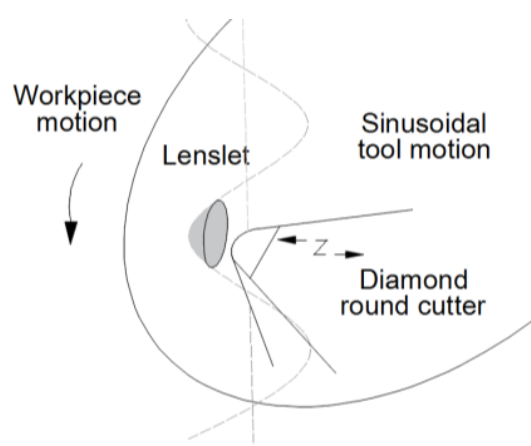

a) Micro lens machining tool path

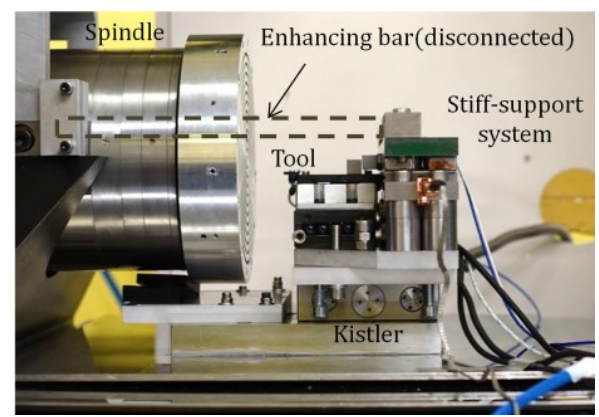

b) Machining setup on diamond turning machine

Fig. 11. Experimental setup for micro lens array machining

The experimental conditions are summarised in Table 2. The finished parts were measured by a white light interferometer (ZYGO CP300) using a 20X objective lens.

Table 2 Experimental conditions

\begin{tabular}{cc}
\hline Name & Value \\
\hline Tool material & Diamond \\
Workpiece material & Electroless plated NiP alloy \\
Tool radius & $0.5 \mathrm{~mm}$ \\
Rake angle & 0 degree \\
Clearance angle & $15 \mathrm{degree}$ \\
Sinusoidal motion frequency & $100 \mathrm{~Hz}$ \\
Sinusoidal motion amplitude & $10 \mu \mathrm{m}, 20 \mu \mathrm{m}$ \\
Lenslet depth & $5 \mu \mathrm{m}, 10 \mu \mathrm{m}$ \\
Flat cutting feed rate & $2 \mu \mathrm{m} / \mathrm{rev}$ \\
Flat cutting depth of cut & $5 \mu \mathrm{m}$ \\
Flat cutting spindle speed & $250 \mathrm{rpm}$ \\
Lubricant & Thin layer of mineral oil
\end{tabular}

\section{Results and discussion}

\subsection{Positioning test results}

As discussed before, the real positioning error of a motion system is not available. Thus the following error readings from sensor feedback are used to verify the analysis approach. The RMS values of the following errors with two different moving masses are shown in Fig. 12 a) and b) respectively. The error bar of each data point indicates the standard deviation of the 32 measurements. The predicted RMS following error is also plotted as a comparison. It can be seen that the estimated following error and the experimental data shows the same trends under both mass conditions. The optimal bandwidths of $874 \mathrm{~Hz}$ and $468 \mathrm{~Hz}$ agree with the measured data. There exists a constant difference of around 10 percent between the estimated value and the measured value, which is attributed to the modelling errors. It is evident that the following error has been reduced at bandwidths below 1 $\mathrm{kHz}$ with the larger moving mass. The following errors keep at the same level between the $1 \mathrm{kHz}$ and $1.5 \mathrm{kHz}$ 
range. This agrees with the analysis results in section 3.3. Bandwidths higher than $1.6 \mathrm{kHz}$ result in unstable loop for the $0.175 \mathrm{~kg}$ mass condition and thus the data is not available.

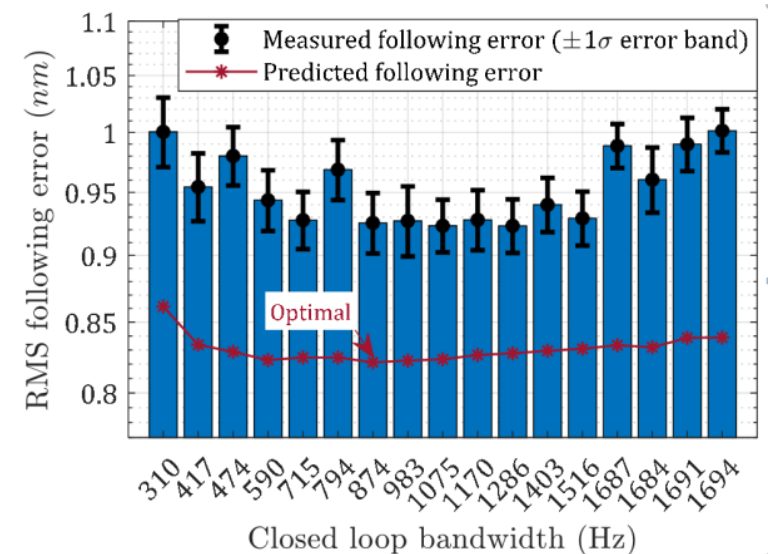

a) Following errors for $0.075 \mathrm{~kg}$ moving mass

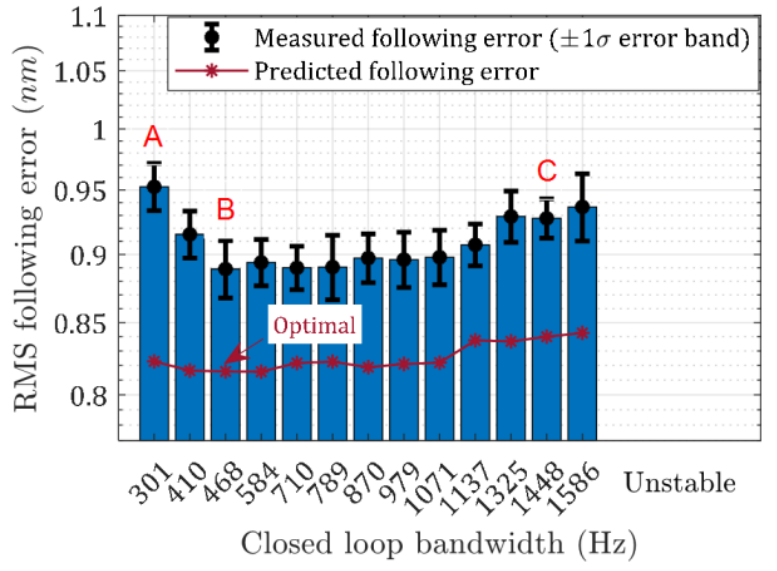

b) Following errors for $0.175 \mathrm{~kg}$ moving mass

Fig. 12. Comparison between measured following error and estimated following error with different moving masses and bandwidths

\subsection{Spectrum analysis of measured errors}

The frequency spectrums of the measured following errors at three bandwidths of $301 \mathrm{~Hz}, 468 \mathrm{~Hz}$ and $1448 \mathrm{~Hz}$, marked as A, B and C in Fig. 12 b), are shown in Fig. 13. It can be seen that under all the three situations, the measured following error spectrum (blue cross) agrees with the synthesised following error spectrum (red) well. At low bandwidth as shown in Fig. 13 a), the low frequency following error is dominated by current noise disturbance. While at high bandwidth as shown in Fig. 13 c), the low frequency following error is greatly reduced due to the better tracking ability, while noises around $1 \mathrm{kHz}$ are greatly amplified. At the optimal bandwidth of $468 \mathrm{~Hz}$ in Fig. $13 \mathrm{~b}$ ), the error contributions from sensor noise and current noise are balanced. The agreed spectrums demonstrate that the error analysis method can predict the frequency components effectively.

With this approach justified, the real positioning error spectrum (shown in green) now can be estimated. There are many differences between the following error spectrum and the real error spectrum. Beyond the closed loop bandwidth, the following error spectrum largely comes from the fake measuring noises. In fact, the tool only has very small physical vibrations at these frequencies. The differences are especially obvious at high bandwidth setting as in Fig. $13 \mathrm{c}$ ). In the low frequency range, the following error is small but the real positioning error is larger. In the high frequency range, the two real vibration peaks at $7.4 \mathrm{kHz}$ and $11.7 \mathrm{kHz}$ are buried in the measuring noises. 


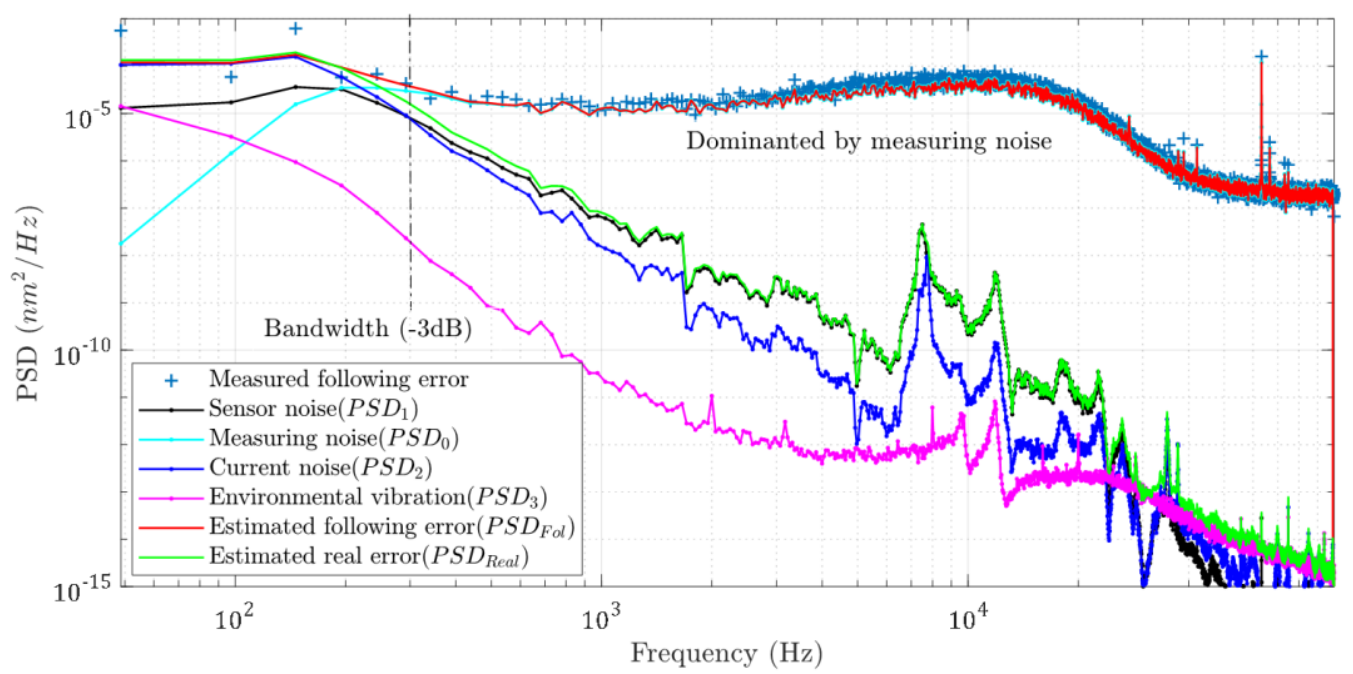

a) At $301 \mathrm{~Hz}$ bandwidth, the low frequency following error is dominated by current noise disturbance.

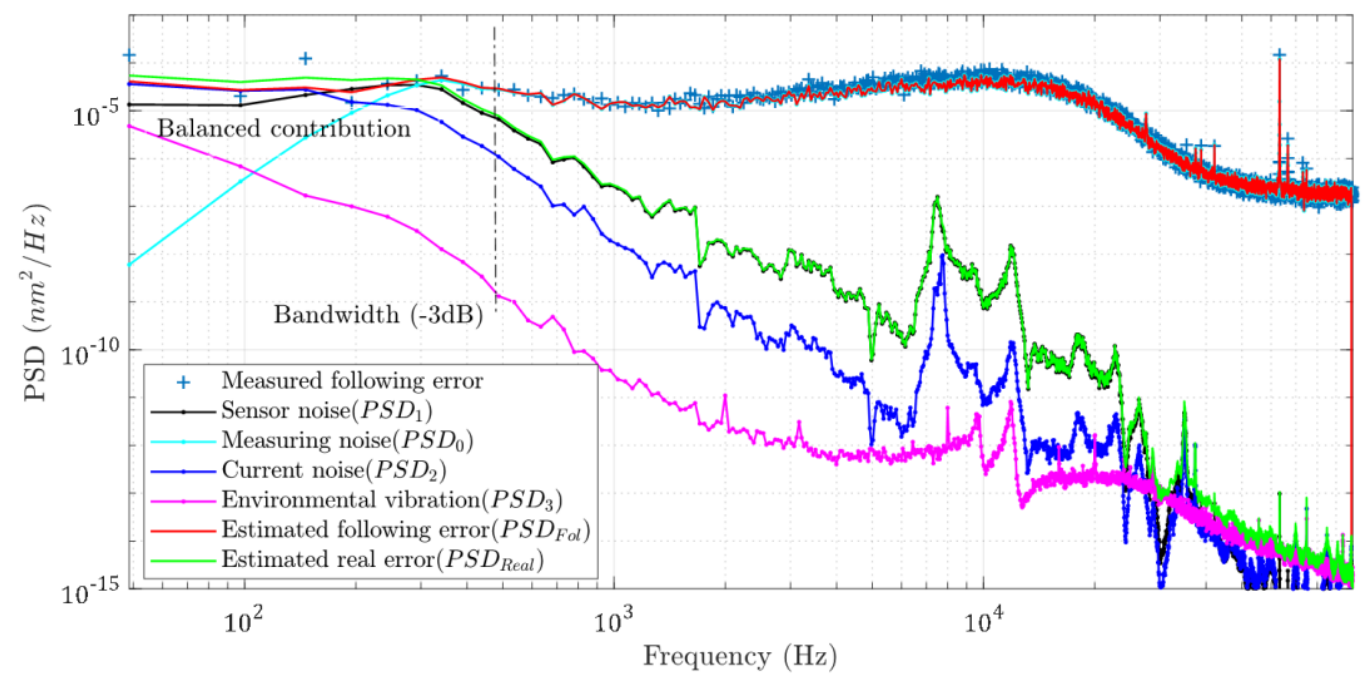

b) At the optimal $468 \mathrm{~Hz}$ bandwidth, the error contributions of PSD1 and PSD2 are balanced.

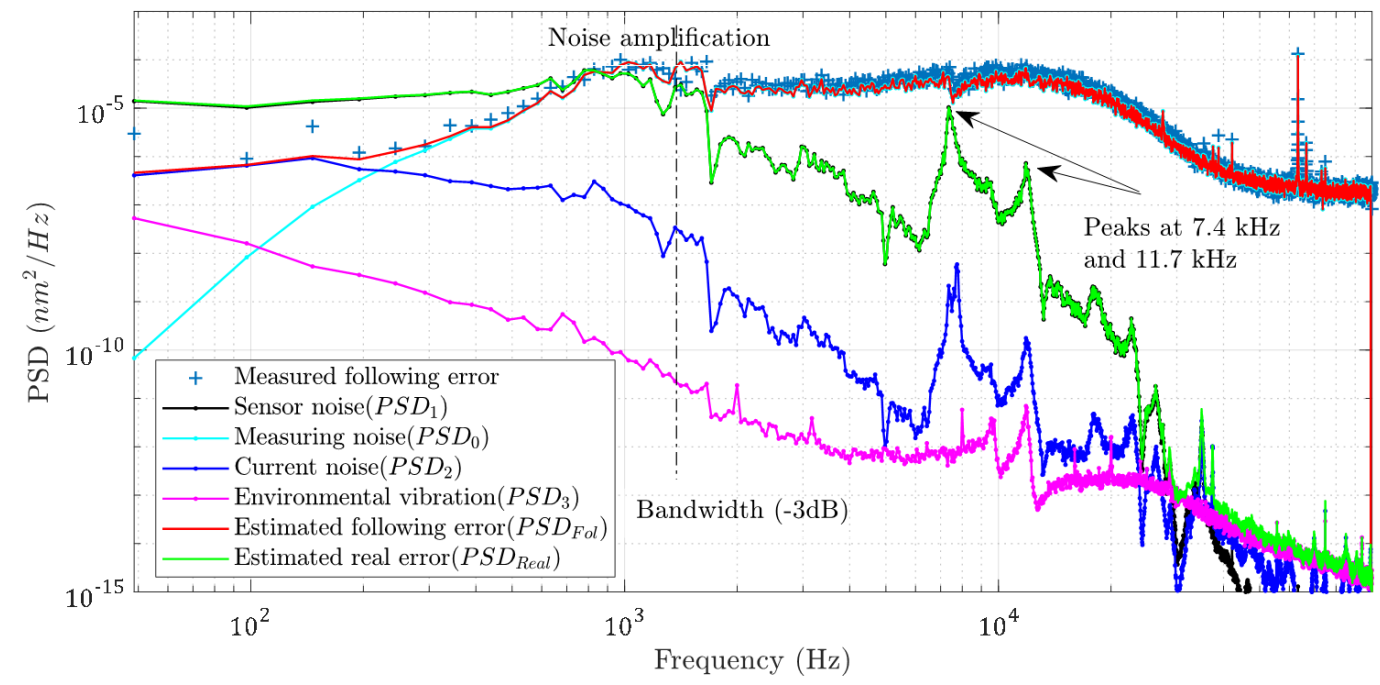

c) At $1448 \mathrm{~Hz}$ bandwidth, the low frequency following error is greatly reduced due to the better tracking ability, while noises around $1 \mathrm{kHz}$ are amplified. High frequency components of real positioning errors are increased.

Fig. 13. Spectrum analysis of predicted following errors and real positioning errors in comparison with experimental results 
The results reveal that the following error signal hardly tells how the tool is vibrating. One sample of the time domain following errors at $468 \mathrm{~Hz}$ bandwidth is shown in Fig. 14. This signal shows around $6 \mathrm{~nm}$ peak to peak value and the RMS value is $0.83 \mathrm{~nm}$. In fact the RMS real positioning error is estimated to be only $0.23 \mathrm{~nm}$ by the model prediction. The peak to peak value will be around $1.4 \sim 2.3 \mathrm{~nm}$, which is $6 \sim 10$ times of the RMS value as a rule of thumb.

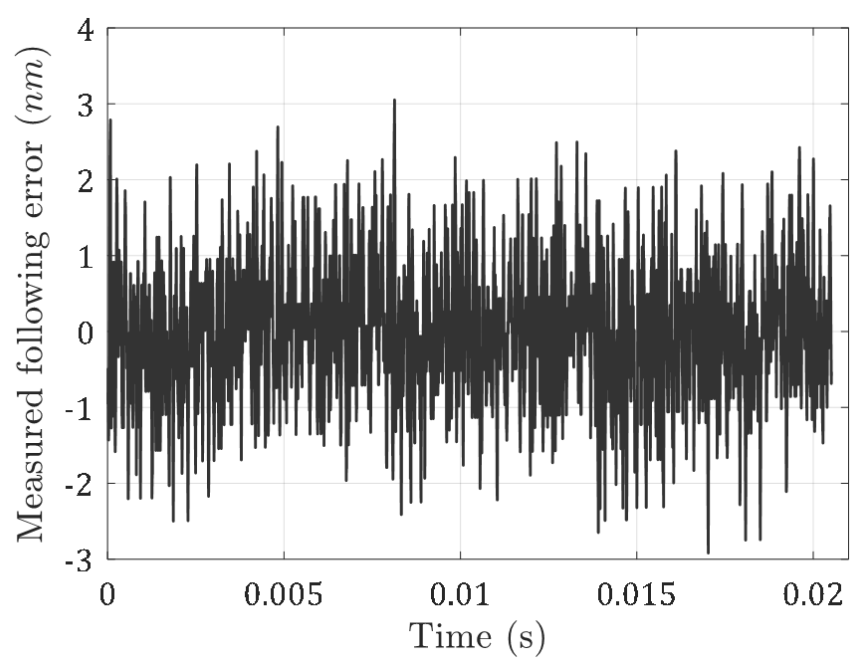

Fig. 14. Following errors read from capacitive sensor feedback at $468 \mathrm{~Hz}$ bandwidth setting

The power percentages of real positioning errors contributed by each disturbance source are shown in Fig. 15. It can be seen that the sensor noise contributes the largest portion of power when the bandwidth is higher than $1 \mathrm{kHz}$. This indicates that a high quality sensor is essential for fast tool servo application. The environmental vibrations only contributed a very small fraction of power for every bandwidth setting. This is attributed to the stiff-support design and the low stiffness and damping of the flexure bearing. If an air bearing is used instead, the contribution will be even lower.

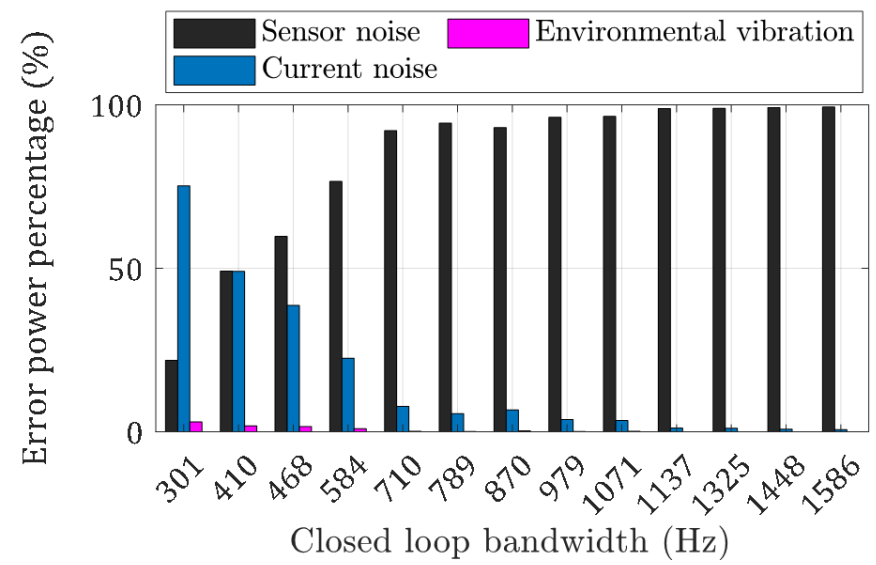

Fig. 15. Error power contribution to the total real positioning error with different bandwidths 


\subsection{Micro lens array machining results}

The real positioning error can be reflected on the machined surface [25-27]. The closed loop bandwidth is set as $1448 \mathrm{~Hz}$ with a moving mass of $0.175 \mathrm{~kg}$, same as in Fig. $13 \mathrm{c}$ ). Flat surface and two different sizes of micro lens with depths of $5 \mu \mathrm{m}$ and $10 \mu \mathrm{m}$ are machined. The measured results by the white light interferometer are shown in Fig. 16. The flat surface shows surface roughness of $1.2 \mathrm{~nm}$ (Ra) with no filter applied.

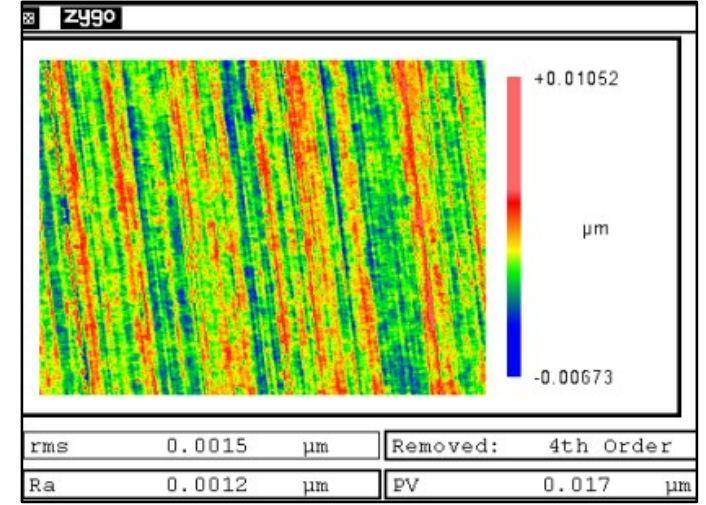

a) Measured flat surface (Size: $0.36 \mathrm{~mm} \times 0.27 \mathrm{~mm}$ )

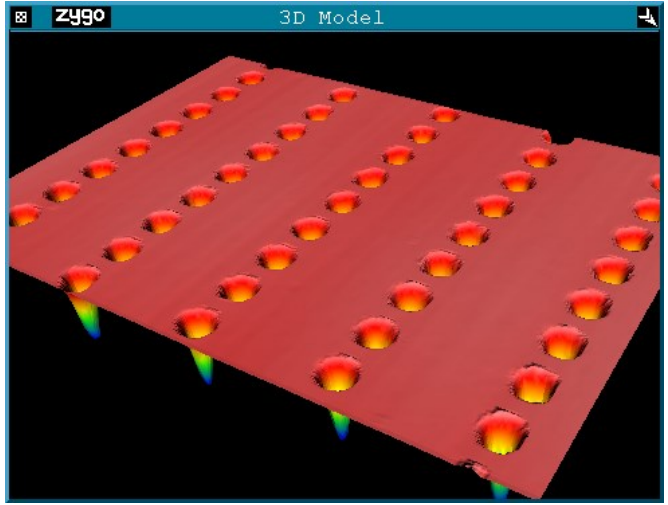

b) Micro lens array structure

Fig. 16. 3D measurement results by white light interferometer

Different from the closed loop positioning tests, the cutting force also plays a role in the cutting process.

The measured and modelled frequency response function from cutting force $(\mathrm{N})$ to sensor voltage $(\mathrm{V})$ is shown in Fig. 17 a). The measured cutting force for the $5 \mu \mathrm{m}$ depth lenslet is shown in Fig. $17 \mathrm{~b}$ ). The force signal is applied as the input of the response model and the simulated tool deviation is also shown in Fig. $17 \mathrm{~b}$ ). It can be seen that the tool deviation gets larger and larger as the absolute cutting force increases. And when the cutting section ends, there is a $180 \mathrm{~nm}$ overshot in the opposite direction. The maximum deviation occurs after the maximum cutting force, or depth of cut. This corresponds to the 12 degree phase lag at $100 \mathrm{~Hz}$ in the frequency response function in Fig. 17 a). This lag is expected to be larger at higher frequencies than $200 \mathrm{~Hz}$. The cutting force for flat area is not distinguishable from instrument noise and thus not studied here.

The effects of cutting force can be reflected in two measurement results, the tool following error and the part form error. The following error from the capacitive sensor is recorded during the lens machining experiment. Fig. 17 b) also shows the measured following errors in three cutting cycles. The error curve poses similar shape as the simulated result. The maximum error of $266 \mathrm{~nm}$ is comparable with the simulated value of $295 \mathrm{~nm}$ although the overshot amount $(34 \mathrm{~nm}$ ) shows some discrepancies with the predicted value. 


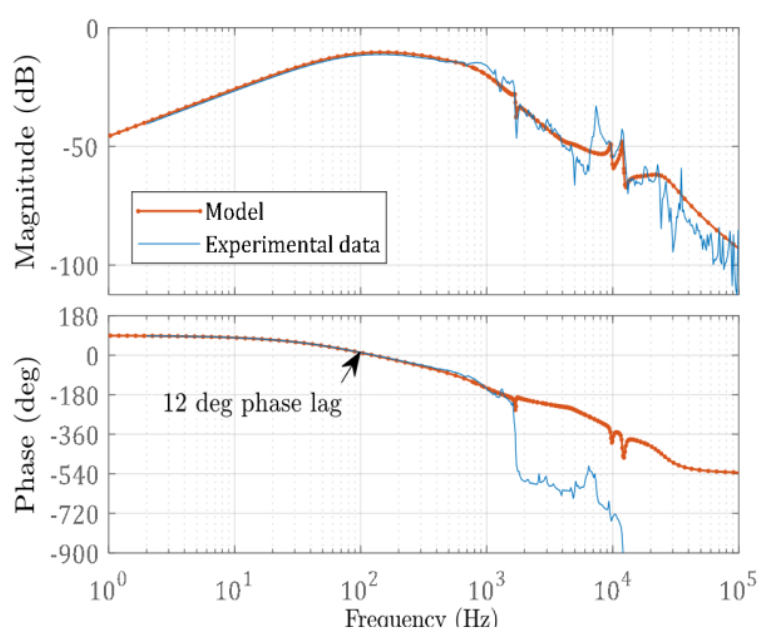

a) Frequency response from cutting force to sensor voltage

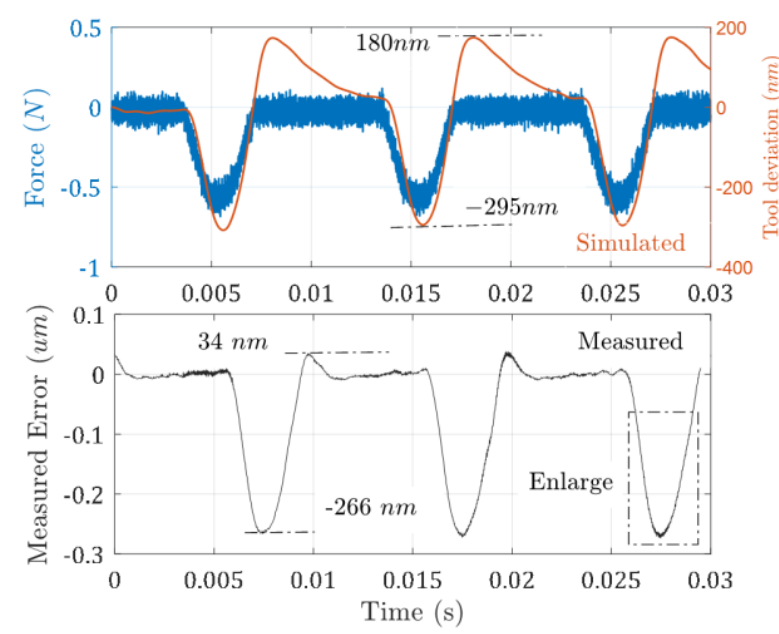

b) Simulated tool deviation with pre-measured force and measured following errors

Fig. 17. Comparison of estimated and measured positioning error caused by cutting force

The form error of the machined micro lens along the cutting direction is shown in Fig. 18. The nominal motion amplitude is $5 \mu \mathrm{m}$ but because the closed loop response has $0.6 \mathrm{~dB}$ overshoot at $100 \mathrm{~Hz}$, the air-cut amplitude of $5.2 \mu \mathrm{m}$ is used as the form reference. The form error curve shows obvious non-symmetric shape. The maximum error of $200 \mathrm{~nm}$ lags behind the maximum depth of cut as suggested in the simulation.

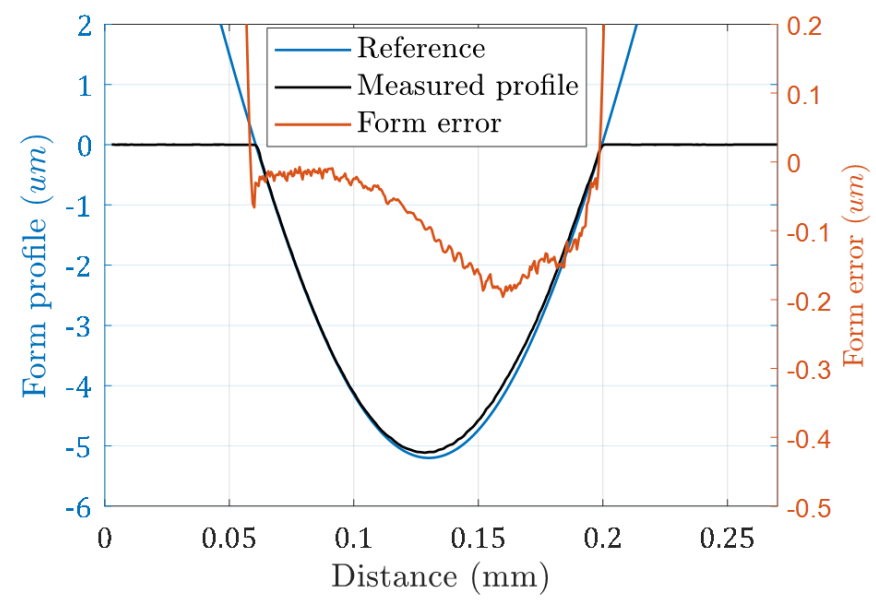

Fig. 18. Form error of the machined micro lens for the $5 \mu \mathrm{m}$ depth lenslet

The high frequency components of form error for both kinds of lenslet are shown in Fig. 19. The spectrum of the cross section profile along the cutting direction is shown on the right. The surface speeds at the cutting point for the $5 \mu \mathrm{m}$ and $10 \mu \mathrm{m}$ depth lenslet are $42.3 \mathrm{~mm} / \mathrm{s}$ and $59.7 \mathrm{~mm} / \mathrm{s}$ respectively. Periodic errors are found at spatial frequencies of $170 \mathrm{~mm}^{-1}$ and $255 \mathrm{~mm}^{-1}$ for the $5 \mu \mathrm{m}$ depth lenslet as shown in Fig. 19 a). This corresponds to $7.2 \mathrm{kHz}$ and $10.8 \mathrm{kHz}$ tool vibrations respectively. The $10 \mu \mathrm{m}$ depth lenslet shows wider error 
period in Fig. $19 \mathrm{~b}$ ) due to the larger surface speed and these vibrations corresponds to $6.6 \mathrm{kHz}$ and $11.5 \mathrm{kHz}$ tool motions.

These vibrations occur at roughly the same frequencies as the two peaks $(7.4 \mathrm{kHz}$ and $11.7 \mathrm{kHz})$ in real positioning error spectrum in Fig. $13 \mathrm{c}$ ) and the cutting force response curve in Fig. $17 \mathrm{a}$ ). This means that the cutting tool has small vibrations at these frequencies and is prone to be excited by the cutting forces at the same frequencies as well. When the cutting force is present, the original vibrations plus the excited vibrations lead to the generation of the periodic form errors.
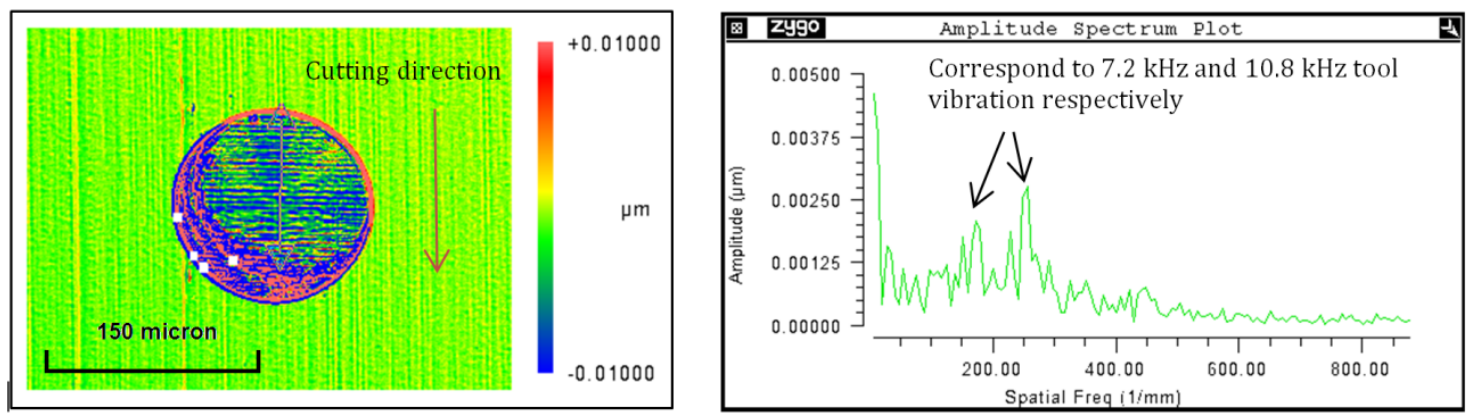

a) Form error map and error spectrum for the $5 \mu \mathrm{m}$ depth lenslet.
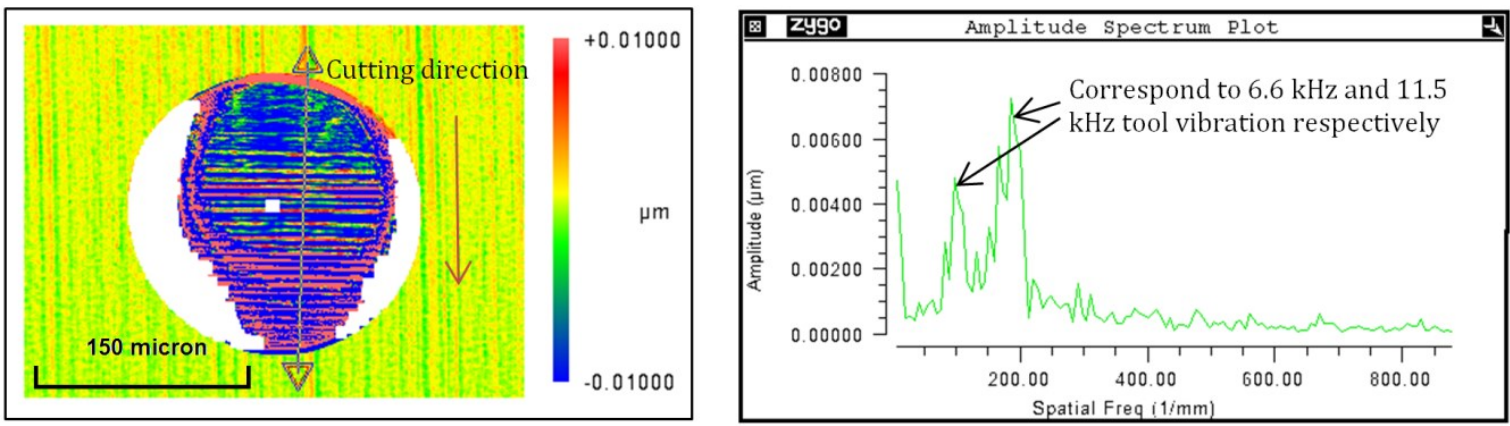

b) Form error map and error spectrum for the $10 \mu \mathrm{m}$ depth lenslet.

Fig. 19. The high frequency components of form errors for both lenslets with $80 \mathrm{~mm}^{-1}$ high pass filter.

\section{Conclusions}

In this paper, a novel tool positioning system is developed and a systematic error analysis approach is thoroughly demonstrated and verified. The complexity of modelling and control has been greatly reduced by stiff-support design which makes detailed error analysis possible. The following conclusions can be drawn in this paper:

(1) The following errors read from the CNC software underestimates the real positioning error at low frequency while overestimates it at high frequency range. The error analysis approach successfully revealed the real tool positioning errors that are mixed with sensor noises. 
(2) Increasing moving mass helps improving the positioning stability. The improvement is not obvious when the major error source is the sensor noise at high bandwidths. The optimal bandwidth, at which errors reach minimum value, turns lower with a larger moving mass.

(3) The cutting force affects both the form error and surface quality in dynamic cutting. The maximum form error doesn't necessarily occur at maximum depth of cut. This can be predicted by analysing the positional response function to cutting force.

(4) Lastly, the cutting experiment demonstrates that it is possible to achieve smooth surface quality without using fluid bearing slides through the stiff-support design, with the benefits of compactness and low costs.

\section{References}

[1] X. Zhang, K. Liu, V. Sunappan, X. Shan, Diamond micro engraving of gravure roller mould for roll-toroll printing of fine line electronics, J. Mater. Process. Technol. 225 (2015) 337-346. doi:10.1016/J.JMATPROTEC.2015.05.032.

[2] S. Scheiding, A.Y. Yi, A. Gebhardt, R. Loose, L. Li, S. Risse, R. Eberhardt, A. Tünnermann, Diamond milling or turning for the fabrication of micro lens arrays: comparing different diamond machining technologies, Opt. Express. 19 (2011) 23938-23951. doi:10.1117/12.874751.

[3] L. Li, A.Y. Yi, Design and fabrication of a freeform prism array for 3D microscopy, J. Opt. Soc. Am. A. 27 (2010) 2613. doi:10.1364/JOSAA.27.002613.

[4] F. Fang, X. Zhang, A. Weckenmann, G. Zhang, C.J. Evans, Manufacturing and measurement of freeform optics, CIRP Ann. - Manuf. Technol. 62 (2013) 823-846. doi:10.1016/j.cirp.2013.05.003.

[5] Z. Zhu, S. To, S. Zhang, Theoretical and experimental investigation on the novel end-fly-cutting-servo diamond machining of hierarchical micro-nanostructures, Int. J. Mach. Tools Manuf. 94 (2015) 15-25. doi:10.1016/J.IJMACHTOOLS.2015.04.002.

[6] M. Mukaida, J. Yan, Ductile machining of single-crystal silicon for microlens arrays by ultraprecision diamond turning using a slow tool servo, Int. J. Mach. Tools Manuf. 115 (2017) 2-14. doi:10.1016/J.IJMACHTOOLS.2016.11.004.

[7] P. Shore, X. Luo, T. Jin, X. Tonnellier, P. Morantz, D. Stephenson, R. Collins, A. Roberts, R. Maymiller, R. Read, Grinding mode of the "BOX” ultra precision free-form grinder, in: Proc. ASPE, 2005: pp. $1-4$.

[8] E. Brinksmeier, O. Riemer, R. Gläbe, B. Lünemann, C. v. Kopylow, C. Dankwart, A. Meier, Submicron 
functional surfaces generated by diamond machining, CIRP Ann. 59 (2010) 535-538. doi:10.1016/J.CIRP.2010.03.037.

[9] E. Brinksmeier, R. Gläbe, C. Flucke, Manufacturing of molds for replication of micro cube corner retroreflectors, Prod. Eng. 2 (2008) 33-38. doi:10.1007/s11740-008-0082-8.

[10] H. Wang, S. To, C.Y. Chan, C.F. Cheung, W.B. Lee, A theoretical and experimental investigation of the tool-tip vibration and its influence upon surface generation in single-point diamond turning, Int. J. Mach. Tools Manuf. 50 (2010) 241-252. doi:10.1016/j.ijmachtools.2009.12.003.

[11] F. Xue, W. Zhao, Y. Chen, Z. Wang, Research on error averaging effect of hydrostatic guideways, Precis. Eng. 36 (2012) 84-90. doi:10.1016/J.PRECISIONENG.2011.07.007.

[12] D.A. Axinte, S. Abdul Shukor, A.T. Bozdana, An analysis of the functional capability of an in-house developed miniature 4-axis machine tool, Int. J. Mach. Tools Manuf. 50 (2010) 191-203. doi:10.1016/J.IJMACHTOOLS.2009.10.005.

[13] Z.Q. Yin, Y.F. Dai, S.Y. Li, C.L. Guan, G.P. Tie, Fabrication of off-axis aspheric surfaces using a slow tool servo, Int. J. Mach. Tools Manuf. 51 (2011) 404-410. doi:10.1016/J.IJMACHTOOLS.2011.01.008.

[14] X. Lu, D.L. Trumper, Ultrafast Tool Servos for Diamond Turning, CIRP Ann. 54 (2005) 383-388. doi:10.1016/S0007-8506(07)60128-0.

[15] X. Lu, Electromagnetically-driven ultra-fast tool servos for diamond turning, Massachusetts Institute of Technology, 2005.

[16] F. Tian, Z. Yin, S. Li, A novel long range fast tool servo for diamond turning, Int. J. Adv. Manuf. Technol. 86 (2016) 1227-1234. doi:10.1007/s00170-015-8282-9.

[17] S. Rakuff, J.F. Cuttino, Design and testing of a long-range, precision fast tool servo system for diamond turning, Precis. Eng. 33 (2009) 18-25. doi:10.1016/j.precisioneng.2008.03.001.

[18] R. Ramesh, M.A. Mannan, A.N. Poo, Error compensation in machine tools - a review: Part I: geometric, cutting-force induced and fixture-dependent errors, Int. J. Mach. Tools Manuf. 40 (2000) 1235-1256. doi:10.1016/S0890-6955(00)00009-2.

[19] R. Ramesh, M.A. Mannan, A.N. Poo, Error compensation in machine tools- a review. Part II: Thermal errors, Int. J. Mach. Tools Manuf. 40 (2000) 1257-1284. doi:10.1016/S0890-6955(00)00010-9.

[20] K. Zhou, J.C. Doyle, Essentials of robust control, Prentice hall Upper Saddle River, NJ, 1998.

[21] P. Gahinet, R. Chen, B. Eryilmaz, B. Singh, Automated PID controller design, using parameters that satisfy a merit function, U.S. Patent 9,886,008, 2018. 
[22] Z. Zhu, S. To, W.-L. Zhu, P. Huang, X. Zhou, Cutting forces in fast-/slow tool servo diamond turning of micro-structured surfaces, Int. J. Mach. Tools Manuf. 136 (2019) 62-75. doi:10.1016/J.IJMACHTOOLS.2018.09.003

[23] L. Jabben, Mechatronic Design of a Magnetically Suspended Rotating Platform, Delft University of Technology, 2007.

[24] P. Huang, S. To, Z. Zhu, Diamond turning of micro-lens array on the roller featuring high aspect ratio, Int. J. Adv. Manuf. Technol. (2018) 1-7. doi:10.1007/s00170-018-1637-2.

[25] S.J. Zhang, S. To, S.J. Wang, Z.W.Z.W. Zhu, A review of surface roughness generation in ultraprecision machining, Int. J. Mach. Tools Manuf. 91 (2015) 76-95. doi:10.1016/j.ijmachtools.2015.02.001.

[26] S.J. Zhang, S. To, G.Q. Zhang, Z.W. Zhu, A review of machine-tool vibration and its influence upon surface generation in ultra-precision machining, Int. J. Mach. Tools Manuf. 91 (2015) 34-42. doi:10.1016/J.IJMACHTOOLS.2015.01.005.

[27] C.L. He, W.J. Zong, J.J. Zhang, Influencing factors and theoretical modeling methods of surface roughness in turning process: State-of-the-art, Int. J. Mach. Tools Manuf. 129 (2018) 15-26. doi:10.1016/J.IJMACHTOOLS.2018.02.001. 